\title{
ORIENTATIONAL ORDER IN THE STABLE BUCKMINSTER FULLERENE SOLVATE $\mathrm{C}_{60} \cdot 2 \mathrm{CBr}_{2} \mathrm{H}_{2}$
}

J. Ye ${ }^{\mathrm{a}}$, M. Barrio ${ }^{\mathrm{a}}$, Ph. Negrier ${ }^{\mathrm{b}}$, N. Qureshi ${ }^{\mathrm{c}}$, I. B. Rietveld ${ }^{\mathrm{d}}$, R. Céolin $^{\mathrm{a}, \mathrm{e}}$, J. Ll. Tamarit ${ }^{\mathrm{a}, *}$

${ }^{a}$ Departament de Física, ETSEIB, Universitat Politècnica de Catalunya, Diagonal 647, 08028 Barcelona, Catalonia, Spain

${ }^{\mathrm{b}}$ LOMA, UMR 5798, F-33400 Talence, France, CNRS, LOMA, UMR 5798, Université de Bordeaux, F-33400 Talence, France

${ }^{c}$ Institut Laue Langevin, 71 avenue des Martyrs - CS 20156 - 38042 GRENOBLE CEDEX 9, France

${ }^{\mathrm{d}}$ Laboratoire de Chimie Physique, CAMMAT, Faculté de Pharmacie, Université Paris Descartes, 4 avenue de l'Observatoire, 75006 Paris, France

'LETIAM, EA7357, IUT Orsay, Université Paris Sud, rue Noetzlin, 91405 Orsay Cedex, France

* Corresponding author: josep.lluis.tamarit@upc.edu

\section{Abstract}

Crystals of the solvate $\mathrm{C}_{60} \cdot 2 \mathrm{CBr}_{2} \mathrm{H}_{2}$ (monoclinic $\mathrm{C} 2 / \mathrm{m}$ ), which is stable in air, were grown by slow evaporation of solutions of $\mathrm{C}_{60}$ in $\mathrm{CBr}_{2} \mathrm{H}_{2}$ at room temperature. The high enthalpy change for the complete desolvation process, $54.9 \mathrm{~kJ} \mathrm{~mol}^{-1}$ of solvent, as well as the relatively large negative excess volume of $-49.6 \AA^{3}$ indicate the presence of strong intermolecular interactions between $\mathrm{C}_{60}$ and $\mathrm{CBr}_{2} \mathrm{H}_{2}$. The strong intermolecular interactions are consistent with an overall orientational order for the $\mathrm{C}_{60}$ and the $\mathrm{CBr}_{2} \mathrm{H}_{2}$ molecules in the solvate as found by the Rietveld refinement of its crystal structure. 


\section{Introduction}

Fullerene $\mathrm{C}_{60}$ is known to be moderately soluble in a large number of solvents, from small quasi-tetrahedral molecules to aromatic ones. Moreover, $\mathrm{C}_{60}$ has a strong tendency to form solvates with solvent molecules, i.e. solvates [1-25].

In many cases the intermolecular interactions between $\mathrm{C}_{60}$ and the guest solvent molecules are strong enough to form a solvate and weak enough to allow for the well-known orientational disorder of the $\mathrm{C}_{60}$ and solvent molecules. It has been demonstrated that due to the relatively weak intermolecular interactions, most solvates are not stable in air and lose solvent molecules through evaporation resulting in disorder within the crystalline structure of desolvated $\mathrm{C}_{60}$ fullerene [26].

The orientational disorder in solvates can complicate the solution of structures by X-ray diffraction [27] and only in a few cases, $\mathrm{C}_{60}$ molecules were found to exhibit orientational order as for example in the recent case of the low-temperature solvate consisting of $\mathrm{C}_{60}$ and cubane $\left(\mathrm{C}_{8} \mathrm{H}_{8}\right)$, which orientational order is claimed to be caused by topological molecular recognition between the convex surface of $\mathrm{C}_{60}$ and concave cubane [28, 29]. Often, structural refinement is only possible by allowing for several rotational orientations of the $\mathrm{C}_{60}$ molecule. For example in certain cases, the solvate structure could be refined using site occupancy factors with two distinct orientations for $\mathrm{C}_{60}$, revealing an obstructed molecular rotation [30, 31]. Moreover, it is often seen that the solvent molecules have different orientations within the $\mathrm{C}_{60}$ interstices. It is clear therefore that the moderate interaction strength between the $\mathrm{C}_{60}$ molecules and its guest molecules is highly tunable, which makes its solvates an interesting subject of study.

In this work, the solvate formation between $\mathrm{C}_{60}$ and dibromomethane, $\mathrm{CBr}_{2} \mathrm{H}_{2}$, has been investigated. Dibromomethane is a relatively small, rigid molecule with $\mathrm{C}_{2 \mathrm{v}}$ symmetry and a significant dipole moment of $1.51 \mathrm{D}$. It is expected to cause anisotropic van der Waals interactions in line with other, previously investigated molecules [32-34]. We will demonstrate that in this case the intermolecular interactions are strong enough to form a solvate that is stable in air and in which the host and guest molecules are orientationally ordered. 


\section{Experimental}

Dibromomethane $\left(\mathrm{CBr}_{2} \mathrm{H}_{2}, \mathrm{M}=173.835 \mathrm{~g} \mathrm{~mol}^{-1}\right)$ was purchased from Aldrich with a purity higher than $99 \%$. Fullerene $\mathrm{C}_{60}\left(\mathrm{M}=720.64 \mathrm{~g} \mathrm{~mol}^{-1}\right)$ was purchased from TermUSA (purity $>99.98 \%$ ). Both compounds were used as received.

Solid $\mathrm{C}_{60}$ was dissolved in $\mathrm{CBr}_{2} \mathrm{H}_{2}$ at room temperature in screw-cap tubes that were subsequently stored for several months in the dark. Black, bright, polyhedral crystals formed at the surface of the colorless solution. The morphology of the crystals (Figure 1) was examined by means of scanning electron microscopy (JEOL-7100F) with a scanning voltage of $20 \mathrm{kV}$.

Differential scanning calorimetry (DSC) and Thermogravimetry (TG) were performed under nitrogen flux at a $2 \mathrm{~K} \mathrm{~min}^{-1}$ scanning rate using the Q100 and Q50 from TA Instruments (New Castle, DE, USA), respectively. Sample masses were weighed in at a precision of 0.01 mg.

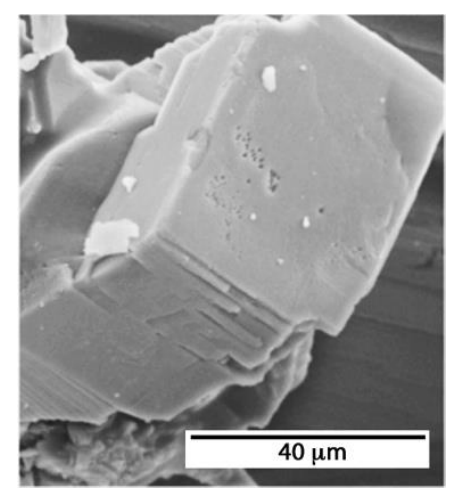

Figure 1. Scanning electron microscopy (SEM) photograph of $\mathrm{C}_{60} \cdot 2 \mathrm{CBr}_{2} \mathrm{H}_{2}$ crystals

High-resolution X-ray powder diffraction was carried out with a transmission mode diffractometer using Debye-Scherrer geometry equipped with a cylindrical position-sensitive detector (CPS120) from INEL (France) containing 4096 channels $\left(0.029^{\circ} 2 \theta\right.$ angular step) with monochromatic $\mathrm{Cu} \mathrm{K \alpha l}(\lambda=1.54061 \AA)$ radiation. The generator power was set to 35 $\mathrm{kV}$ and $35 \mathrm{~mA}$. The deviation in the angular linearity of the PSD (position-sensitive detector) was corrected following the recommended procedure by external calibration using the cubic phase of $\mathrm{Na}_{2} \mathrm{Ca}_{3} \mathrm{Al}_{2} \mathrm{~F}_{4}$ and cubic spline fitting [35]. Peak position determinations were carried out after pseudo-Voigt fitting. Crystals were gently crushed and introduced in a Lindemann capillary $(0.5 \mathrm{~mm}$ diameter $)$ rotating perpendicularly to the X-ray beam during the experiments to improve the average over the crystallite orientations.

A liquid nitrogen 700 series Cryostream Cooler from Oxford Cryosystems (U.K.) was used to control the temperature during the measurements. For the temperature dependent 
measurements the heating rate in between data collection was $1.33 \mathrm{~K} \mathrm{~min}^{-1}$ and the sample temperature was equilibrated for at least $10 \mathrm{~min}$ after which the $\mathrm{X}$-ray diffraction profiles were recorded isothermally for at least $60 \mathrm{~min}$. Longer acquisition time patterns, $9 \mathrm{~h}$, were recorded for structural and refinement purposes at room temperature. Pawley fits, indexing, structure solution, and Rietveld refinement were performed with the Materials Studio Program (Version 5.5) from Accelrys (San Diego, CA) [36]. An independent FullProf structural analysis was carried out to verify the refinement results.

\section{Results}

An X-ray diffraction pattern was obtained from the crystals (see Figure 1) extracted from the surface of the colorless solution at room temperature. After the crystals were left at room temperature in contact with air for several days, the same X-ray patterns were obtained. It can therefore be assumed that the solvate is stable in air.

Systematic absences for the space group assessment were compatible with the centered monoclinic space group $\mathrm{C} 2 / \mathrm{m}$. To determine the structure of the solvate, atom coordinates of the individual molecules $\mathrm{C}_{60}$ and $\mathrm{CBr}_{2} \mathrm{H}_{2}$ were used from the literature and fitted in the obtained diffraction patterns. For the Rietveld refinement, a rigid-body constraint was used for $\mathrm{CBr}_{2} \mathrm{H}_{2}$. The position and orientation of the molecules were refined with a single overall isotropic displacement parameter and preferred orientation using the March-Dollase formula [37]. The refinement results are depicted in Figure 2, together with the experimental pattern and the difference between the refined pattern and the experimental one. The values of the final Rietveld refinement are summarized in Table 1.

Surprisingly, the $\mathrm{C}_{60}$ molecules appeared to be orientationally ordered in the current solvate. For confirmation, an independent Rietveld refinement of the structural model was carried out with the FullProf program. In a first step, the $\mathrm{C}_{60}$ molecule was modeled as a spherical shell with the scattering density of 60 carbon atoms homogeneously distributed on a sphere with a radius of $3.59 \AA$, which represents a freely rotating molecule. The $\mathrm{CBr}_{2} \mathrm{H}_{2}$ molecule was modeled as a rigid body with the atom coordinates taken from Podsiadło et al. [32]. The local coordinate system was set with the 2-fold rotation axis of the $\mathrm{CBr}_{2} \mathrm{H}_{2}$ molecule pointing along the local $z$ axis (the local coordinate system is defined by $x\|a, y\| b$ and $z \|(a x b)$ with $\theta=\varphi=\chi=0$ ), which therefore permits to rotate the molecule around its 2-fold rotation axis by the angle $\chi$ independently of its orientation in the unit cell. A first refinement clearly 
shows that the $\mathrm{CBr}_{2} \mathrm{H}_{2}$ molecule is oriented with its 2-fold rotation axis parallel to the monoclinic $b$ axis, i. e. $\theta=\varphi=90$ degrees.

In a second step, the $\mathrm{C}_{60}$ molecule was modeled as a rigid body with its 2 -fold rotation axis along the local $z$ axis. A clear improvement of the refinement is apparent between the spherical-shell model with the agreement factor, $\mathrm{R}_{\mathrm{F}}$, equal to 8.0 and the rigid-body model with $\mathrm{R}_{\mathrm{F}}=4.2$, which strongly suggests that the $\mathrm{C}_{60}$ molecule is not freely rotating. The resulting orientation is such that its 2 -fold rotation axis is aligned with the monoclinic $b$ axis just like the $\mathrm{CBr}_{2} \mathrm{H}_{2}$ molecule (i.e. $\theta=\varphi=90$ degrees).

Rotating the two molecules each around their individual 2-fold rotation axes corresponding to the angle $\chi$ for both molecules exhibits a strong influence on the agreement factor, in particular for dibromomethane, however also $\mathrm{C}_{60}$ has a clear single minimum within one $\pi$ periodicity (see Figure 3 ). The results confirm the orientational order of dibromomethane with the same alignment of its rotation axis in relation to the monoclinic cell. A dynamic rotation of the $\mathrm{CBr}_{2} \mathrm{H}_{2}$ molecule around its 2-fold axis can be ruled out due to the very strong dependence of the angle $\chi$ on $\mathrm{R}_{\mathrm{F}}$ (see Figure 3 ), which demonstrates that the molecule must have a fixed orientation, i.e. with the Br ligands pointing towards the longer diagonal of the a-c plane (see Figure 4). The final structural parameters obtained from the last refinement were virtually the same as those obtained by means of the Materials Studio package. In the case of $\mathrm{C}_{60}$ the results are not as clear-cut as for $\mathrm{CBr}_{2} \mathrm{H}_{2}$, but the difference between the global minimum and the local minima is convincing enough to expect $\mathrm{C}_{60}$ to be mainly stuck in a single orientation, even if a stepwise arrested rotation cannot be excluded due to the many local minima. 


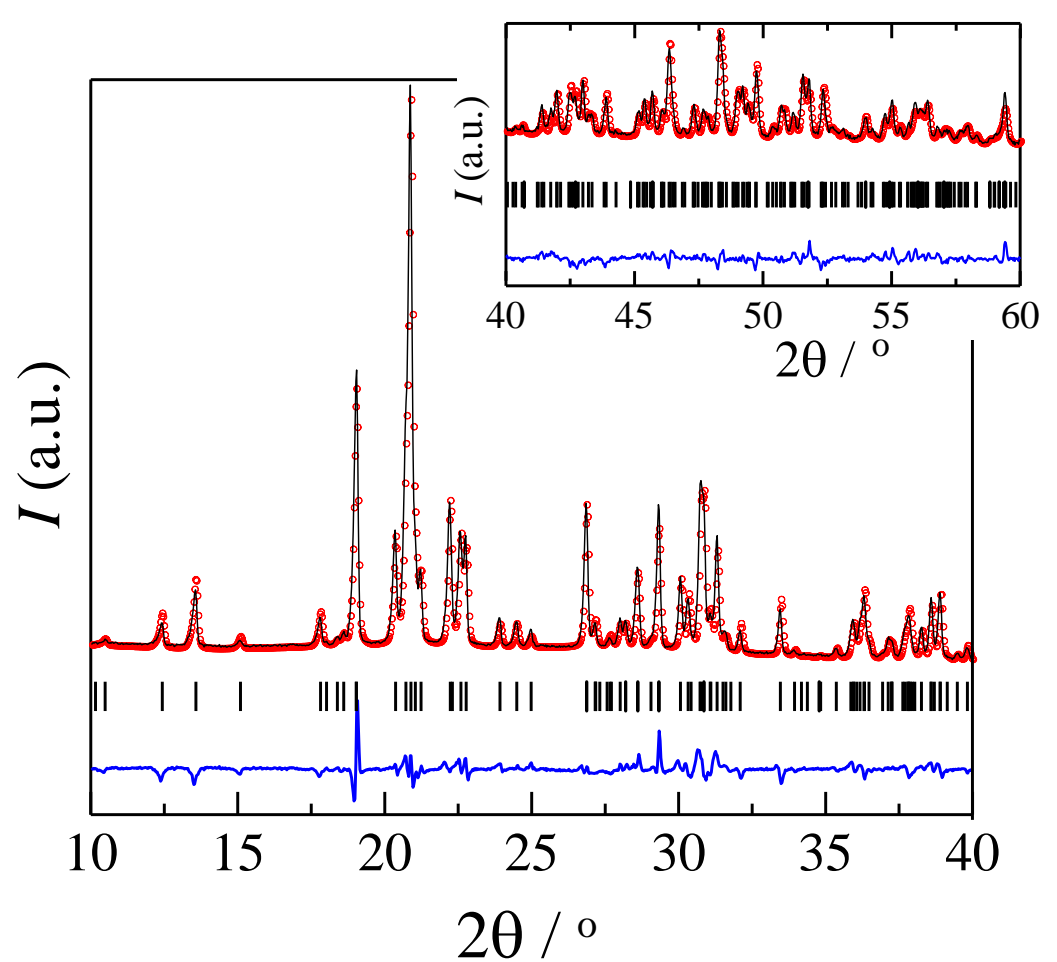

Figure 2. Experimental (red circles) and calculated (black line) diffraction patterns along with the difference profile (blue line) and Bragg reflections (vertical bars) of the monoclinic $C 2 / \mathrm{m}$ space-group of the $\mathrm{C}_{60} \cdot 2 \mathrm{CBr}_{2} \mathrm{H}_{2}$ solvate at room temperature. The inset corresponds to the scale for the data between 40 and $60^{\circ} 2 \theta$.

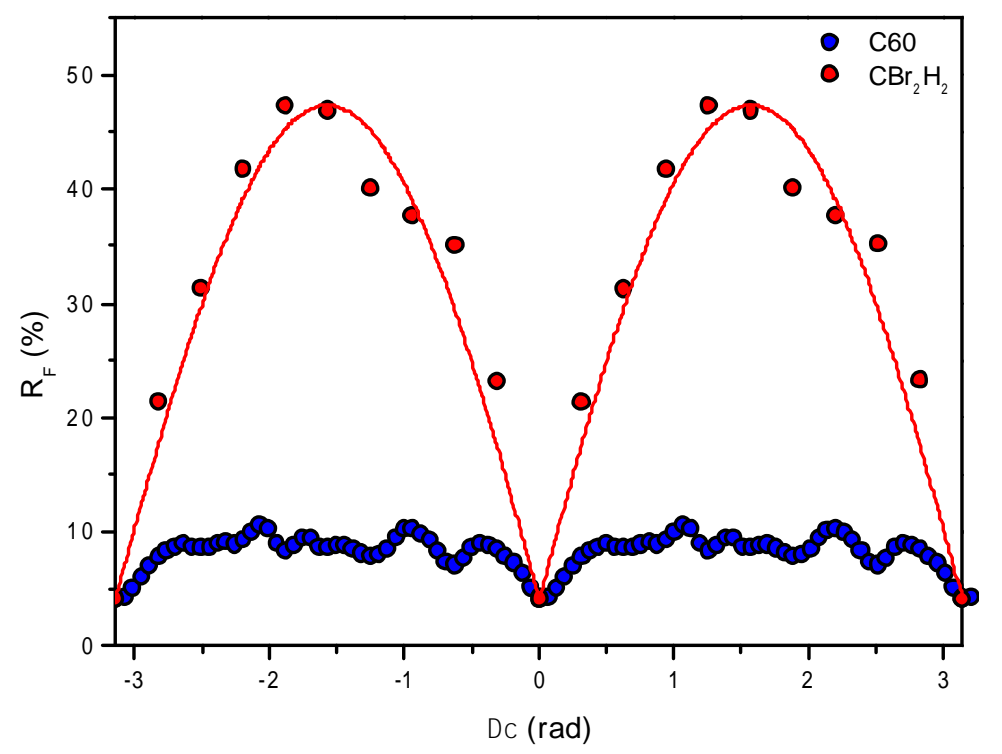

Figure 3. The crystallographic agreement factor, $\mathrm{R}_{\mathrm{F}}$, as a function of the rotation angle around the 2-fold rotation axis of $\mathrm{C}_{60}$ (blue dots) and of $\mathrm{CBr}_{2} \mathrm{H}_{2}$ (red dots). A clear optimal 
orientation can be observed around the 2-fold rotation axes, which is more strongly pronounced for $\mathrm{CBr}_{2} \mathrm{H}_{2}$. The angular dependence exhibits the expected pi-periodicity, however, due to the more complex structure of $\mathrm{C}_{60}$ and its 3-fold and 5-fold rotation axes, additional local minima are present.
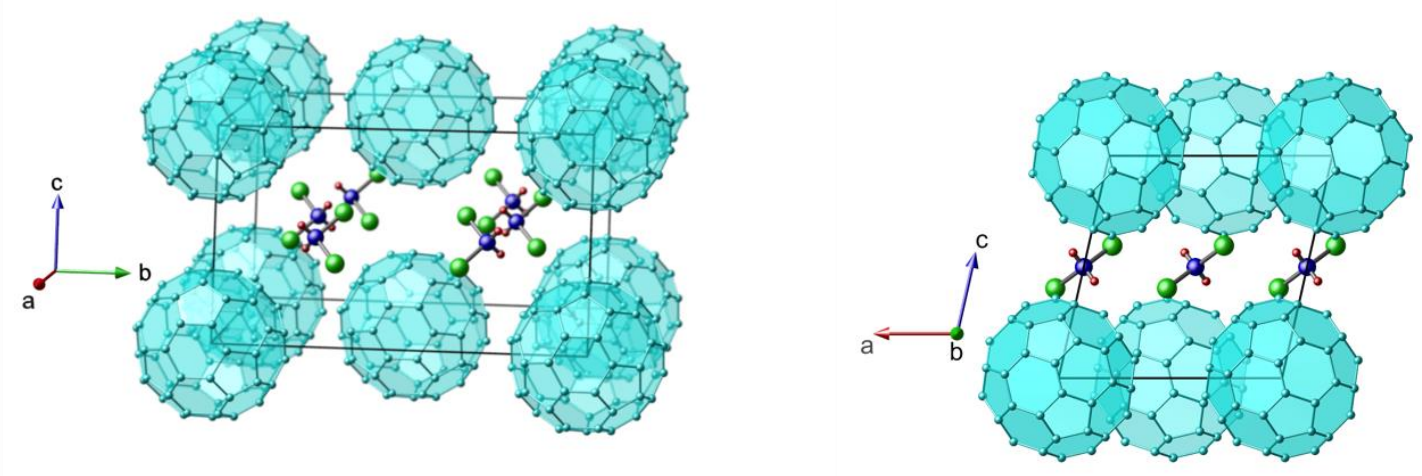

Figure 4. The molecular positions in the crystal structure of $\mathrm{C}_{60} \cdot 2 \mathrm{CBr}_{2} \mathrm{H}_{2}$ approximately along the [100] direction (left panel) and along the [010] direction (right panel).

Table 1. Crystal structure information and Materials Studio results of the Rietveld refinement for the $\mathrm{C}_{60} \cdot 2 \mathrm{CBr}_{2} \mathrm{H}_{2}$ solvate

\begin{tabular}{cc}
\hline Chemical Formula & $\mathrm{C}_{60} \cdot 2 \mathrm{CBr}_{2} \mathrm{H}_{2}$ \\
\hline$M / \mathrm{g} \cdot \mathrm{mol}^{-1}$ & 1068.31 \\
\hline $2 \theta$-Angular Range & $7-80^{\circ}$ \\
\hline Space group & $C 2 / m$ \\
\hline$a / \AA$ & $9.9001 \pm 0.0004$ \\
$b / \AA$ & $17.446 \pm 0.001$ \\
$c / \AA$ & $10.1013 \pm 0.0004$ \\
$\alpha /{ }^{\circ}$ & 90 \\
$\beta /^{\circ}$ & $102.769 \pm 0.002$ \\
$\gamma /{ }^{\circ}$ & 90 \\
\hline$V / Z / \AA^{3}$ & $1701.5 \pm 0.4$ \\
\hline$Z\left(Z^{\prime}\right)$ & $2(1 / 4)$ \\
\hline Temperature & $293 \mathrm{~K}$ \\
\hline$D_{\mathrm{x}} / \mathrm{g} \cdot \mathrm{cm}{ }^{-3}$ & $2.085 \pm 0.001$ \\
\hline Wavelength $(\mathrm{Cu}$ K $\alpha 1)$ & $\lambda=1.5406 \AA$ \\
\hline $2 \theta$-shift (zero correction) & $0.0264 \pm 0.0012$ \\
\hline Profile Parameters & $0.509 \pm 0.015$ \\
\hline Na & \\
\hline Reliability Parameters & \\
\hline
\end{tabular}




\begin{tabular}{cc}
\hline$R_{\mathrm{wp}}$ & $6.08 \%$ \\
\hline$R_{\mathrm{p}}$ & $4.24 \%$ \\
\hline$U$ & $0.124 \pm 0.017$ \\
$V$ & $-0.037 \pm 0.010$ \\
$W$ & $0.0175 \pm 0.0016$ \\
\hline Peak width parameters & \\
\hline Overall isotropic temperature $^{2}$ & $0.0332 \pm 0.0006$ \\
\hline factor, $U / \AA^{2}$ & \\
\hline Asymmetry Correction & \\
(Finger-Cox-Jephcoat) $^{38}$ & $0.0280 \pm 0.0003$ \\
\hline$H / L$ & $0.0280 \pm 0.0003$ \\
\hline$S / L$ & \\
\hline Preferred Orientation & \\
(March-Dollase) $^{37}$ & $0.517 \pm 0.030$ \\
\hline$a^{*}$ & $0.838 \pm 0.019$ \\
\hline$b^{*}$ & $0.189 \pm 0.036$ \\
\hline$c^{*}$ & $1.055 \pm 0.007$ \\
\hline$R_{0}$ &
\end{tabular}

A few crystals together with a small quantity of mother liquor were subjected to thermogravimetric analyses. After the recorded mass reached a constant value at room temperature, the sample was assumed to be mother liquor free. It was subsequently heated to $550 \mathrm{~K}$ (Figure 5) with a constant heating rate of $2 \mathrm{~K} \mathrm{~min}^{-1}$. Experimental mass loss was found to be ca. $32 \%$, i.e. very close to the expected value of $33 \%(=2 \times 173.8 / 1067.7)$ for the $\mathrm{C}_{60}: \mathrm{CBr}_{2} \mathrm{H}_{2}=1: 2$ molar ratio. The TG curve in Figure 5 clearly demonstrates that the desolvation process takes place in two overlapping steps. It could indicate the formation of a solvate with a lower stoichiometry or the existence of a desorption process following the desolvation of the 1:2 solvate.

The same procedure as for the TG measurements was followed for the DSC measurements (Figure 5). Again, it can be observed that two thermal effects are convoluted as the endothermic peak $\left(T_{\text {onset }}=326 \mathrm{~K}\right)$ clearly consists of two overlapping peaks. In fact, the derivative of the mass loss with respect to the temperature (gray curve in Figure 5, which results from the TG measurements) mimics the DSC signal even if a small shift in temperature exists. 


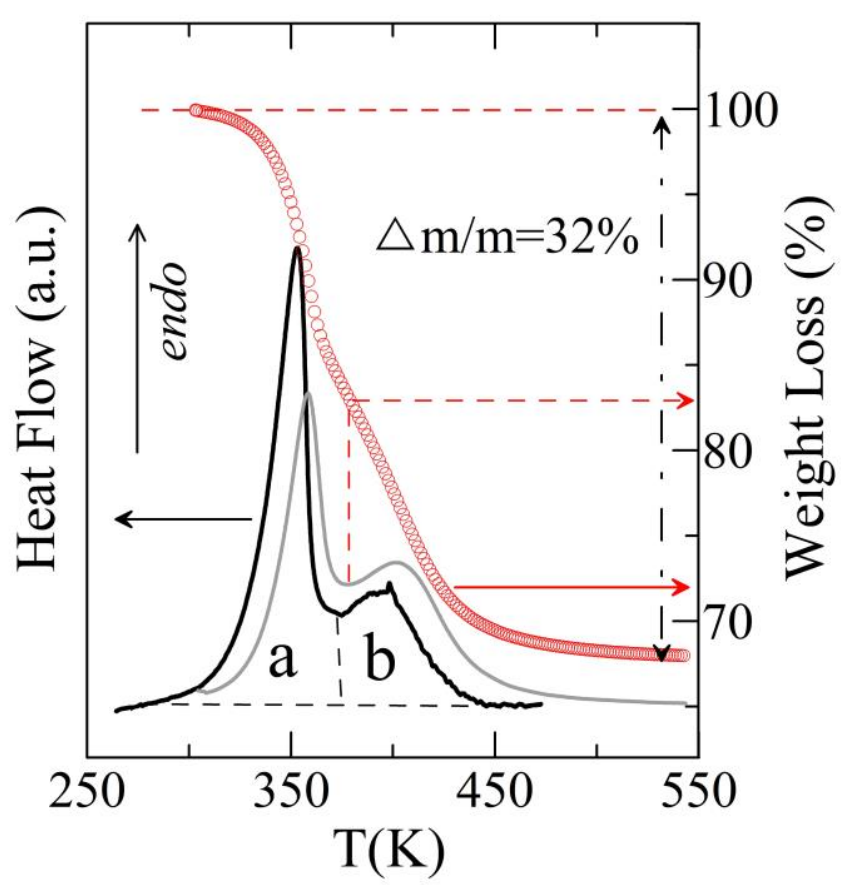

Figure 5. Differential scanning calorimetry curve (black, left axis) and thermogravimetry curve (red points, right axis) as a function of the temperature for the $\mathrm{C}_{60} \cdot 2 \mathrm{CBr}_{2} \mathrm{H}_{2}$ solvate. Grey curve corresponds to the derivative of the weight loss with respect to the temperature. The dashed red arrow indicates the mass loss at the minimum of the derivative (see text). The endothermic effect recorded by DSC and associated to the complete desolvation can be separated into peaks $\mathbf{a}$ and $\mathbf{b}$, which respectively represent enthalpy changes of $73.9 \mathrm{~J} \mathrm{~g}^{-1}$ and $29.1 \mathrm{~J} \mathrm{~g}^{-1}$ related to the initial mass of the solvate.

To investigate the two convoluted peaks in the desolvation process more closely, X-ray diffraction measurements were carried out on crystals in a closed capillary as a function of the temperature. Figure 6 shows several patterns between room temperature and $385 \mathrm{~K}$, which is near the end of the second endothermic process. Patterns at intermediate temperatures reveal that the Bragg peaks of the monoclinic solvate remain clearly present up to $330 \mathrm{~K}$ above which the diffraction pattern appears of desolvated $\mathrm{C}_{60}$ partially amorphized by crystal defects and stacking faults as commonly observed after desolvation of $\mathrm{C}_{60}$ solvates [16, 21, 22, 39]. It indicates that the existence of a second solvate with a smaller stoichiometry is not likely. 


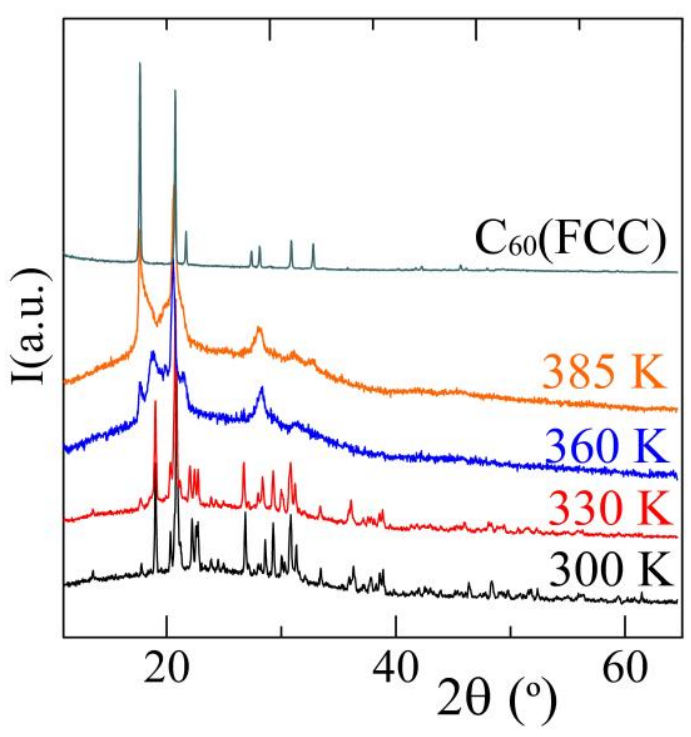

Figure 6. $\mathrm{X}$-ray patterns of the $\mathrm{C}_{60} \cdot 2 \mathrm{CBr}_{2} \mathrm{H}_{2}$ solvate as a function of the temperature. The pattern of pure $\mathrm{FCC}_{60}$ is shown at the top for reference purposes.

\section{Discussion}

The desolvation process, which can be written as

$$
\mathrm{C}_{60} \cdot 2 \mathrm{CBr}_{2} \mathrm{H}_{2}(\mathrm{~s}) \rightarrow \mathrm{C}_{60}(\mathrm{~s})+2 \mathrm{CBr}_{2} \mathrm{H}_{2}(\mathrm{~g})
$$

occurs in two steps as demonstrated by DSC as well as thermogravimetry by peaks $\mathbf{a}$ and $\mathbf{b}$ in Figure 5. The enthalpy change of the process is found to be $103 \mathrm{~J} \mathrm{~g}^{-1}$ of solvate $\left(110.0 \mathrm{~kJ} \mathrm{~mol}^{-}\right.$ ${ }^{1}$ of solvate) or $316 \mathrm{~J} \mathrm{~g}^{-1}$ of solvent (54.9 $\mathrm{kJ} \mathrm{mol}^{-1}$ of solvent) by summing over peaks a and b as a whole. The total enthalpy is higher than the sublimation enthalpy of $\mathrm{CBr}_{2} \mathrm{H}_{2}$ of $46.2 \mathrm{~kJ}$ $\mathrm{mol}^{-1}$ (obtained by adding the melting enthalpy, $9.2 \mathrm{~kJ} \mathrm{~mol}^{-1}$, and the vaporization enthalpy, $37 \mathrm{~kJ} \mathrm{~mol}^{-1}$ [40]). It implies that $\mathrm{CBr}_{2} \mathrm{H}_{2}$ and $\mathrm{C}_{60}$ attract each other relatively strongly in the $\mathrm{C}_{60} \cdot 2 \mathrm{CBr}_{2} \mathrm{H}_{2}$ solvate. The TG-curve indicates that the first peak is accompanied with a weight loss of $16.3 \%$ of the initial mass. This corresponds to the loss of about one of the two moles of $\mathrm{CBr}_{2} \mathrm{H}_{2}$ from the solvate $\mathrm{C}_{60} \cdot 2 \mathrm{CBr}_{2} \mathrm{H}_{2}$ as $0.163 \times 1068.31 \mathrm{~g} \mathrm{~mol}^{-1}=174.1 \mathrm{~g} \mathrm{~mol}^{-1}$, which is very close to the molar mass of the solvent of $173.8 \mathrm{~g} \mathrm{~mol}^{-1}$.

The bimodal thermal effect associated with the desolvation process was not caused by the formation of a second solvate as demonstrated by the X-ray experiments as a function of the temperature in Figure 6, because impure fcc C60 is observed in the temperature range related to peak $\mathbf{b}$ and no additional peaks of a possible new solvate have been observed. Because the desolvation process must occur first, the second step will be vaporization of the released solvent. Thus, after the desolvation process, $\mathrm{CBr}_{2} \mathrm{H}_{2}$ may first liquefy and remain temporarily 
adsorbed to the $\mathrm{C}_{60}$ followed by evaporation. This can be summarized with the following two steps:

$$
\begin{gathered}
\left.\mathrm{C}_{60} \cdot 2 \mathrm{CBr}_{2} \mathrm{H}_{2}(\mathrm{~s}) \rightarrow \mathrm{C}_{60}(\mathrm{FCC})+\mathrm{CBr}_{2} \mathrm{H}_{2} \text { (l, adsorbed }\right) \\
\mathrm{C}_{60}(\mathrm{FCC})+2 \mathrm{CBr}_{2} \mathrm{H}_{2}(1, \text { adsorbed }) \rightarrow \mathrm{C}_{60}(\mathrm{FCC})+2 \mathrm{CBr}_{2} \mathrm{H}_{2}(\mathrm{~g})
\end{gathered}
$$

Peak a, which has an enthalpy change of $73.9 \mathrm{~J} \mathrm{~g}^{-1}\left(78.95 \mathrm{~kJ} \mathrm{~mol}^{-1}\right)$ of initial solvate according to the partial area deconvolution procedure available in TA Instruments software, consists of the complete destruction of the solvate network, step (2), and the evaporation of about $1 \mathrm{~mol}$ of solvent, half the step (3). Thus, the enthalpy change related to step (2) is found by subtracting the vaporization enthalpy of one mole of solvent (i.e. step 3) from $78.95 \mathrm{~kJ}$ $\mathrm{mol}^{-1}$ of initial solvate. This leads to $\Delta \mathrm{H}(2)=32.8 \mathrm{~kJ} \mathrm{~mol}^{-1}$ of initial solvate. The enthalpy change related to peak b (29.1 J g $\mathrm{J}^{-1}$ of initial solvate) belongs to $83.7 \%$ of the remaining sample, which coincidentally has a 1:1 mol ratio (one mol of solvent per mol of $\mathrm{C}_{60}$ ). The enthalpy can therefore be expressed as $34.77 \mathrm{~J} \mathrm{~g}^{-1}$ of remaining sample or as $31 \mathrm{~kJ} \mathrm{~mol}^{-1}$ of desorbing and evaporating solvent. This value is of the same order as the enthalpy needed to desorb similar organic solvents from graphitized thermal carbon [41].

The X-ray diffraction results and the Rietveld refinement reveal a monoclinic (space group $C 2 / m$ ) crystal structure with overall orientationally ordered $\mathrm{C}_{60}$ and $\mathrm{CBr}_{2} \mathrm{H}_{2}$ molecules. The structure is characterized by alternating planes consisting of either $\mathrm{C}_{60}$ or guest molecules stacked along the c axis. The $\mathrm{CBr}_{2} \mathrm{H}_{2}$ molecule is located at $[0,0.2710(2), 0.5]$ in the unit cell, while the position $[0,1 / 3,1 / 2]$ corresponds to the prismatic void $[1 / 3,2 / 3,1 / 2]$ of the hexagonal parent structure of $\mathrm{C}_{60}$ with space group $\mathrm{P} 6 / \mathrm{mmm}$. In fact, the monoclinic $b$ axis in the $\mathrm{C}$-centered cell is approximately $2 \times \cos \left(30^{\circ}\right)$ times the hexagonal $a$ axis. Therefore, due to the identical packing and void filling, the structure of $\mathrm{C}_{60} \cdot 2 \mathrm{CBr}_{2} \mathrm{H}_{2}$ can be regarded as a distorted hexagonal one.

The refinement results appear to point to orientationally ordered molecules, both for $\mathrm{C}_{60}$ and $\mathrm{CBr}_{2} \mathrm{H}_{2}$ in the solvate structure. This is quite unusual, because in general in solvates with small halogen-methane or -ethane derivatives, the C60 molecules, and often the solvent molecules too, are found to exhibit orientational disorder. For example, solvent molecules possessing $\mathrm{C}_{2 \mathrm{v}}$ symmetry, such as $\mathrm{CBr}_{2} \mathrm{Cl}_{2}$ or $\mathrm{CBr}_{2}\left(\mathrm{CH}_{3}\right)_{2}$, were found to be orientationally disordered in solvates with a hexagonal structure, whereas the packing of such solvates is very similar to the present one, as illustrated in Figure 7A. 
The overall orientational order in the $\mathrm{CBr}_{2} \mathrm{H}_{2}$ solvate cannot be explained by the dipole moment of the solvent of $1.51 \mathrm{D}$, because $\mathrm{CBr}_{2}\left(\mathrm{CH}_{3}\right)_{2}$ possesses a similar value of $1.64 \mathrm{D}$ in contrast to that of $\mathrm{Br}_{2} \mathrm{CCl}_{2}$ of $0.2 \mathrm{D}$, which both exhibit orientational disorder in their respective solvates. To take a closer look at the host-guest interactions, excess volumes can be studied. Such volumes are defined as the difference between the measured volume of a solvate (defined as $V_{\text {unit cell }} / Z$, i.e. $1701.5 / 2=850.75 \AA^{3}$ ) and the sum of the molecular volumes of the $\mathrm{C}_{60}$ and solvent molecules from their respective pure structures. For $\mathrm{C}_{60}$, the molecular volume is $710 \AA^{3}$ from its FCC structure and the molecular volume of $\mathrm{Br}_{2} \mathrm{CH}_{2}$ was determined as $95 \AA^{3}$ from the structure by Kawaguchi et al. [33] at $253 \mathrm{~K}$. Accordingly, the excess volume is found to be negative: $850.75-(710+2 \times 95) \approx-49.3 \AA^{3}$, which is relatively high and demonstrates the strong interaction between the $\mathrm{C}_{60}$ and solvent molecules. This excess value must be considered as the lower bound because molecular volume of $\mathrm{Br}_{2} \mathrm{CH}_{2}(95$ $\AA^{3}$ ) has been obtained at $253 \mathrm{~K}$ due to the lack of density values at room temperature.

The packing coefficient, $\eta$, of the present solvate can be determined as the van der Waals volumes of the solvate molecules divided by the measured solvate volume $V_{\text {unit cell }} / Z$. The van der Waals volume of $\mathrm{C}_{60}$ is known to be $526 \AA^{3}$ (the volume of a sphere with a ca. $5 \AA$ radius) and that of the $\mathrm{CBr}_{2} \mathrm{H}_{2}$ molecule has been determined through the Kitaigorodsky method [42] as $66.3 \AA^{3}$. With these values, a packing coefficient has been found of 0.773 , which is higher than the packing coefficient of close packed $\mathrm{C}_{60}(\eta=0.74)$ and that of the monoclinic $(C 2 / \mathrm{m})$ low-temperature ordered phase of $\mathrm{CBr}_{2} \mathrm{H}_{2}$ at $183 \mathrm{~K}(\eta=0.70)$. It demonstrates that the interaction between $\mathrm{C}_{60}$ and $\mathrm{CBr}_{2} \mathrm{H}_{2}$ is strong confirming the likelihood of an overall orientational order of the solvate molecules. Figure 7B illustrates the high packing coefficient for the $\mathrm{CBr}_{2} \mathrm{H}_{2}$ solvate compared to other hexagonal solvates containing $\mathrm{C}_{60}$ and similar solvent molecules. The only comparably sized solvate that exhibits orientational order for $\mathrm{C}_{60}$ and the solvent molecule too, the low-temperature orthorhombic solvate with $\mathrm{CS}_{2}$ has a similar packing coefficient, ca. 0.78, as the present solvate (cf. Figure 7B). The corresponding high-temperature monoclinic solvate of $\mathrm{CS}_{2}$ on the other hand, which exhibits orientational disorder, possesses a considerably lower packing coefficient, ca. 0.76 (see Figure 7B) [29]. 

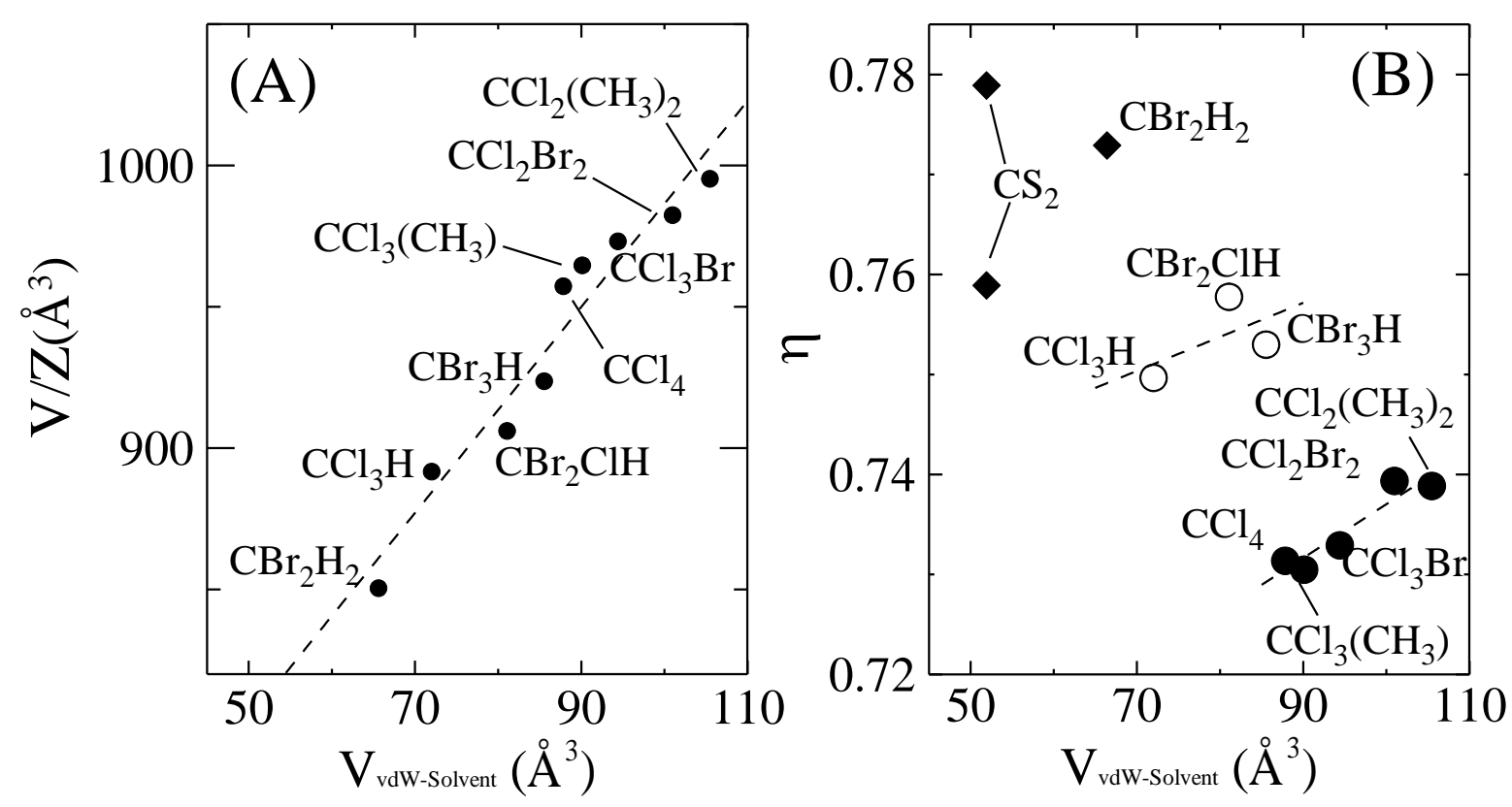

Figure 7. (A) Measured, weighted unit-cell volumes (V/Z) of $\mathrm{C}_{60}$ solvates against the van der Waals volume of its solvent molecule and (B) the packing coefficient as a function of the van der Waals volume of its solvent molecule. In (B), the values for the monoclinic (higher value) and orthorhombic (lower value) of $2 \mathrm{C}_{60} \cdot 3 \mathrm{CS}_{2}$ solvate have been added. Dashed lines are guides to the eyes.

\section{Conclusions}

The hexagonal solvate $\mathrm{C}_{60} \cdot 2 \mathrm{CBr}_{2} \mathrm{H}_{2}$, which is stable in air, has been structurally and thermodynamically characterized. The $\mathrm{C}_{60}$ molecules possess a hexagonal base structure, which is deformed and becomes monoclinic due to the presence of solvent molecules. Notwithstanding the similarity of $\mathrm{CBr}_{2} \mathrm{H}_{2}$ with other solvent molecules that form $\mathrm{C}_{60}$ hexagonal solvates, in particular those with the same $\mathrm{C}_{2 \mathrm{v}}$ molecular symmetry as $\mathrm{CBr}_{2} \mathrm{Cl}_{2}$ and $\mathrm{CBr}_{2}\left(\mathrm{CH}_{3}\right)_{2}$, the $\mathrm{CBr}_{2} \mathrm{H}_{2}$ solvate exhibits overall orientational order for both the $\mathrm{C}_{60}$ and the $\mathrm{CBr}_{2} \mathrm{H}_{2}$ molecules, rarely seen in the other solvates. The orientational order is consistent with the solvate's stability, which has a high negative excess volume and a high desolvation enthalpy. All these physical properties demonstrate the strong host-guest interactions. Although the correct space group symmetry of the solvate is monoclinic $(\mathrm{C} 2 / \mathrm{m})$, the overall packing is very similar to the hexagonal packing found in many other solvates.

It is clear that the present solvate with $\mathrm{CBr}_{2} \mathrm{H}_{2}$ exhibits overall orientational order due to strong interactions between $\mathrm{C}_{60}$ and its solvent molecule. This stands in clear contrast to the recent case of orientational order in the solvate mentioned in the introduction of $\mathrm{C}_{60}$ and 
cubane, which was claimed to be caused by topological molecular recognition between the convex surface of $\mathrm{C}_{60}$ and the concave cubane [28].

\section{Acknowledgements}

This work has been supported in part by the Spanish Ministry of Science and Innovation (grants FIS2014-54734-P) and the Catalan Government (grant 2014 SGR-581).

\section{References}

1. M.F. Meidine, P. B. Hitchcock, H. W. Kroto, R. Taylor, and D. R. M. Walton, J.Chem.Soc.,Chem. Commun. 20, 1534 (1992).

2. R. Céolin, V. Agafonov, D. André, A. Dworkin, H. Szwarc, J. Dugué, B. Keita, L. Nadjo, C. Fabre, and A. Rassat, Chem. Phys. Lett. 208, 259 (1993).

3. R.S. Ruoff, D.S.Tse, R. Malhotra, and D. C. Lorents, J. Phys. Chem. 97, 3379 (1993).

4. H. B. Bürgi, R. Restori, D. Schwarzenbach, A. L. Balch, J. W. Lee, B. C. Noll, and M. M. Olmstead, Chem. Mater. 6, 1325 (1994) .

5. S. Pekker, G. Faigel, K. Fodor-Csorba, L. Gránásy, E. Jakab, and M. Tegze, Solid State Commun. 83, 423 (1992).

6. A. Graja, and R. Swietlik, Synth. Met. 70. 1417 (1995).

7. R. Céolin, V. Agafonov, B. Bachet, A. Gonthier-Vassal, H. Szwarc, S. Toscani, G. Keller, C. Fabre, and A. Rassat, Chem. Phys. Lett. 244, 100 (1995)

8. R. Swietlik, P. Byszewski, and E. Kowalska, Chem.Phys. Lett. 254, 73 (1996).

9. M. Barrio, D. O. Lopez, J. Ll. Tamarit, H. Szwarc, S. Toscani, and R. Céolin, Chem. Phys. Lett. 260, 78 (1996).

10. H. He, J. Barras, J. Foulkes, and J. Klinowski, J. Phys. Chem. B. 101,117 (1997).

11. R. Céolin, V. Agafonov, S. Toscani, M. F. Gardette, A. Gonthier-Vassal, and H. Szwarc, Fullerene Sci. Technol. 5, 559 (1997).

12. F. Michaud, M. Barrio, S. Toscani, D.O. López, J.Ll. Tamarit, V. Agafonov, H. Szwarc and R. Céolin, Phys. Rev. B. 57, 10351 (1998).

13. I. E. Grey, M. J. Hardie, T. J. Ness, and C. L. Raston, Chem.Commun. 12, 1139 (1999).

14. R. Céolin, J. Ll. Tamarit, D. O. López, M. Barrio, V. Agafonov, H. Allouchi, F. Moussa and H. Szwarc. Chem. Phys. Lett. 314, 21 (1999).

15. A. Talyzin, and U. Jansson, J. Phys. Chem. B. 104, 5064 (2000). 
16. S. Toscani, H. Allouchi, J. Ll. Tamarit, D.O. López, M. Barrio, V. Agafonov, A. Rassat, H. Szwarc and R. Céolin. Chem. Phys. Lett. 330, 491 (2000).

17. F. Michaud, M. Barrio, D. O. López, J. Ll. Tamarit, V. Agafonov, S. Toscani, H. Szwarc, and R.Céolin. Chem. Mater. 12, 3595 (2000).

18. L. Wang, B. B. Liu, S. D. Yu, M. G. Yao, D. D. Liu, Y. Y. Hou, T. Cui, G. T. Zou, and B. Sundqvist, Chem. Mater. 18, 4190 (2006).

19. L. Wang, B. B. Liu, D. D. Liu, M. G. Yao, Y. Y. Hou, S. D. Yu, T. Cui, D. M. Li, and G. T. Zou, Adv.Mater.18, 1883 (2006).

20. R. Céolin, J. Ll. Tamarit, M. Barrio, D.O. López, S. Toscani, H. Allouchi, V. Agafonov, and H. Szwarc. Chem. Mater. 13, 1349 (2001).

21. P. Espeau, M. Barrio, D.O. López, J. Ll. Tamarit, R. Céolin, H. Allouchi, V. Agafonov, F. Masin and H. Szwarc, Chem. Mater. 14(1), 321 (2002).

22. M. Barrio, D.O. López, J. Ll. Tamarit, P. Espeau and R. Céolin, Chem. Mater. 15(1), 288 (2003).

23. R. Céolin, D.O. López, M. Barrio, J.Ll. Tamarit, P. Espeau, B. Nicolaï, H. Allouchi, and R. J. Papoular, Chem. Phys. Lett. 399, 401 (2004).

24. R. Céolin, J. Ll. Tamarit, M. Barrio, D. O. López, P. Espeau, H. Allouchi, and R.J. Papoular, Carbon. 43(2), 417 (2005).

25. R. Céolin, D. O. López, B. Nicolaï, P. Espeau, M. Barrio, H. Allouchi, and J. Ll. Tamarit, Chem. Phys. 342(1-3), 78 (2007).

26. H. Y. He, J. Barras, J. Foulkes and J. Klinowski, J. Phys. Chem. B. 101, 117 (1997).

27. M. Jansen and G. Waidmann, Z. Anorg. Allg. Chem. 621, 14 (1995).

28. S. Pekker, É. Kováts, G. Oszlányi, G. Bényei, G. Klupp, G. Bortel, I. Jalsovszky, E. Jakab, F. Borondics, K. Kamarás, M. Bokor, G. Kriza, K. Tompa, and G. Faigel, Nature. Mater. 4, 764 (2005).

29. M. M. Olmstead, F. Jiang, and A. L. Balch, Chem. Commun. 6, 483 (2000).

30. A. L. Balch, J. W. Lee, B. C. Noll and M. M. Olmstead, J. Chem. Soc. Chem. Commun. 1, 56 (1993).

31. M. V. Korobov, A. L. Mirakian, N. V. Avramenko, E. F. Valeev, L. S. Neretin, Y. L. Slovokhotov, A. L. Smith, G. Olofsson and R. S. Ruo, J. Phys. Chem. B. 102, 3712 (1998).

32. M. Podsiadlo, K. Dziubek, M. Szafranski and A. Katrusiak, Acta. Cryst. B. 62, 1090 (2006). 
33. T. Kawaguchi, M. Hijikigawa, Y. Hayafuji, M. Ikeda, R. Fukushima, and Y. Tomiie, Bull. Chem. Soc. Jpn. 46, 53(1973).

34. B. H. Torrie, O. S. Binbrek, I. P. Swainson, and B. M. Powell, Molec. Phys. 97, 581 (1997).

35. J. Ballon, V. Comparat, J. Pouxe, Nucl. Instrum. Methods. 217, 213 ( 1983 ) .

36. MS Modeling (Materials Studio) version 5.5, http://www.accelrys.com /mstudio/ms_modeling.

37. W. A. Dollase, J. Appl. Crystallogr. 19, 267 (1986)

38. L. W. Finger, D. E. Cox and A. P. Jephcoat, J. Appl. Cryst. 27, 892 (1994).

39. G. B. M. Vaughan, Y. Chabre, and D. Dubois, Europhys. Lett. 31, 525 (1995).

40. J. Laynez, I. Wadsö, A. Haug, J. Songstad, A. Pilotti, Acta Chem. Scand. 26, 3148 (1972)

41. N. N. Avgul and A. V. Kiselev, in Chemistry and Physics of Carbon, edited by P. L. Walker, Jr. (Dekker, New York, 1970) Vol. 6, p. 39.

42. A. I. Kitaigorodskii, Mixed Crystals. (Berlin: Springer-Verlag, 1984). 